\title{
Self reported injury patterns among competitive curlers in the United States: a preliminary investigation into the epidemiology of curling injuries
}

\author{
J C Reeser, R L Berg
}

Br J Sports Med 2004;38:e29 (http://www.bjsportmed.com/cgi/content/full/38/5/e29). doi: 10.1136/bjsm.2003.010298

Objective: To investigate the injury patterns among competitive curlers.

Methods: Participants at two curling championship events were asked to complete injury history questionnaires.

Results: 76 curlers (39\%) participated; $79 \%$ of these reported curling related musculoskeletal pain, most commonly involving the knee (54\%), back (33\%), and shoulder (20\%). Sweeping and delivering the stone were most likely to provoke symptoms. Time loss injuries were estimated to occur at a rate of 2 per 1000 athlete exposures.

Conclusions: Curling appears to be a relatively safe winter sport. Prospective studies are needed to confirm these preliminary findings and to further define the risk factors for curling related injuries.

\footnotetext{
C
} urling is a sport with great lore and a tradition of sportsmanship and fellowship. Invented in Scotland in the 16th century, it is a game of marksmanship and strategy that has enjoyed Olympic medal status since the Nagano Games (fig 1). In terms of participation, curling must be considered a "minor" sport. Approximately 1.5 million people in 36 countries curl, $80 \%$ of whom reside in Canada and only $1 \%$ in the USA.

The basic objective of curling is to deliver a $20 \mathrm{~kg}$ block of polished granite (the "stone") into a target at the end of a $44.5 \times 4.75 \mathrm{~m}$ sheet of ice. Two principal motor skills are involved: stone delivery and sweeping (fig 2). Traditionally, the stone is delivered by lifting it up and back before swinging it forward onto the ice. The "no-backswing" delivery (in which the stone is slid back on the ice before propelling it forward) (fig $2 \mathrm{~A}$ ) is recommended by USA Curling as "ideal for people with shoulder or back problems." After releasing the stone, the curler will typically slide along the ice, observing the stone's trajectory, while assuming a position of extreme knee and hip flexion on the nondominant ("tuck") side (fig 2B). The stone will follow a curvilinear path that depends on its speed and the coefficient of friction between ice and stone. Sweeping (fig 2C) smoothes the ice in front of the stone, diminishing the amount of "curl" and maintaining the velocity of the stone so that it travels further. Sweeping demands sustained forward flexion at the waist and vigorous repetitive upper limb movement, while maintaining one's balance on the ice.

There is little published research on curling sport medicine. A thorough search of the literature revealed no published studies on curling injury epidemiology. This brief report describes the results of a preliminary investigation into the injury patterns among competitive curlers in the USA.

\section{METHODS}

Competitors at two national championship curling events were invited to participate voluntarily in the study, which was approved by the institutional review board. Injury questionnaires were distributed to all athletes participating in the 1999 USA Curling National Championship (NC) in Duluth, Minnesota and the inaugural "Silver Cup" Men's National Club Championship (SC) held later that winter in Madison, Wisconsin. The questionnaire was a curling specific modification of an instrument designed to collect retrospective sports injury histories. ${ }^{1}$ The collected data were analysed by $\chi^{2}$ testing. A probability $(p)$ value of $\leqslant 0.05$ was adopted as a measure of statistically significant associations.

\section{RESULTS}

Of the 113 questionnaires circulated at the NC, 56 (50\%) were returned ( 33 male and 23 female players). At the SC, 20 questionnaires were returned (25\% response rate), yielding a combined 39\% response rate (76/193). Table l summarises relevant demographic and exposure information.

Overall, $79 \%$ of the study participants experienced curling related musculoskeletal aches and pains. Eighty eight per cent of NC respondents experienced occasional discomfort they attributed to curling, compared with 55\% of the SC respondents $(p=0.002)$. There was no significant difference in the anatomical distribution of musculoskeletal symptoms between the two cohorts. Sweeping the stone (55\%) and delivering the stone $(50 \%)$ were the skills most provocative of symptoms (fig $2 \mathrm{~A}-\mathrm{C}$ ). Collectively, symptoms of knee (54\%), back $(33 \%)$, and shoulder pain $(20 \%)$ were most prevalent (table 2). Knee pain was most often reported in the "tuck" knee, which is typically flexed well beyond $90^{\circ}$ during stone delivery. Sixty two per cent of those with knee pain were symptomatic in their tuck knee, while $31 \%$ complained of bilateral discomfort.

Time loss injuries (defined as injuries resulting in the loss of at least one day of training or competition) were

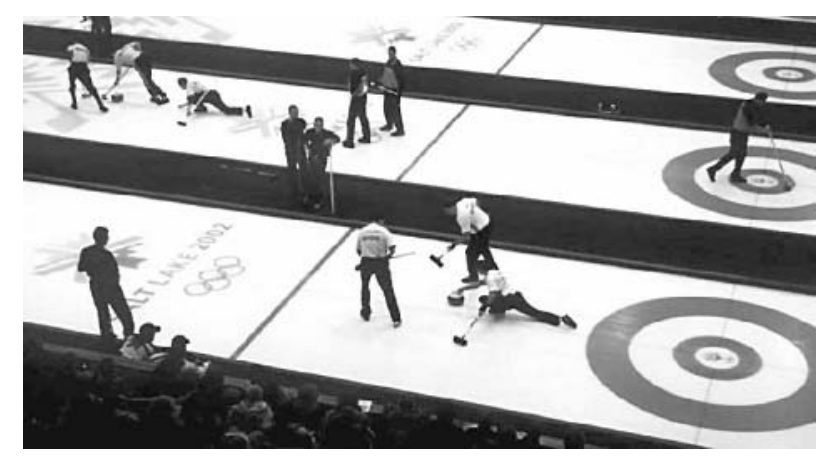

Figure 1 Curling action during the 2002 Winter Olympic Games. 

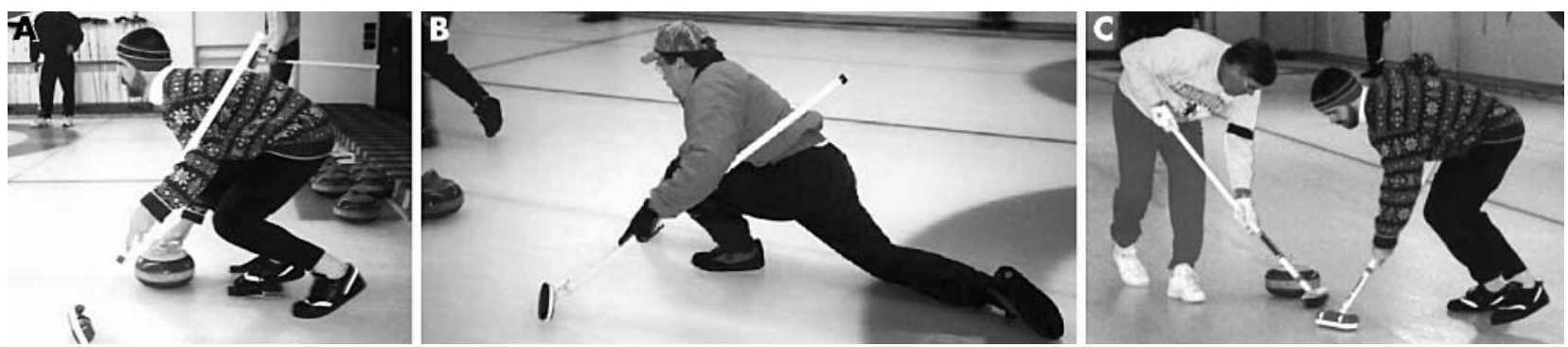

Figure 2 Stone delivery (A and B) and sweeping (C), the two principal curling motor skills.

Table 1 Demographic and exposure data of curling questionnaire respondents

\begin{tabular}{lll}
\hline Variable & Result & p Value \\
\hline Demographic variables & $41.9(20$ to 64$)$ & \\
Age (years) & $20.4(3$ to 47$)$ & \\
Years curled & $2.6(1$ to 8$)$ & \\
Athlete exposures per week & $5.6(3$ to 8$)$ & \\
Months curled per year & & \\
& & \\
Tournament dependent variables & $6.1(4.1)$ & 0.01 \\
Tournaments per year (NC) & $3.8(2.9)$ & 0.048 \\
Tournaments per year (SC) & 44 & \\
Per cent consuming alcohol while curling (NC) & 70 & \\
Per cent consuming alcohol while curling (SC) & & \\
\hline & Values are mean (range) or mean (SD) unless stated otherwise. \\
NC: National Championship; SC: Silver Cup; SD: standard deviation. &
\end{tabular}

uncommon (table 3). Although alcohol is regularly consumed during recreational curling events, none of the four athletes injured by falling on the ice had been consuming alcohol at the time of injury. Three time loss injuries were attributed to sweeping (specifically, bending at the waist or repetitive upper limb use). Based on estimates of annual curling exposure, the time loss injury incidence for NC respondents was calculated as 2.3 injuries/1000 athlete exposures, while SC respondents suffered time loss injuries at a rate of 2.0/ 1000 athlete exposures.

\section{DISCUSSION}

Symptoms of knee, back, and shoulder pain appear to be common among competitive curlers, and may be related to repetitive upper limb use and the sustained knee and spine flexion demanded by the sport's two principal skills. Symptoms of musculoskeletal overload were more common among the NC respondents, possibly reflecting the greater number of exposures reported by that cohort.

Although one purported advantage of the "no backswing" delivery technique is reduced shoulder loading, there was no significant association between delivery technique and the incidence of shoulder pain. Furthermore, there was no association between limb dominance and shoulder pain,

Table 2 Most common areas of curling related musculoskeletal pain

\begin{tabular}{lllll}
\hline Location & NC male & NC female & SC & Total \\
\hline Knee & $61 \%$ & $57 \%$ & $40 \%$ & $54 \%$ \\
Back & $36 \%$ & $39 \%$ & $20 \%$ & $33 \%$ \\
Shoulder & $12 \%$ & $26 \%$ & $25 \%$ & $20 \%$ \\
Hips & $12 \%$ & $9 \%$ & $10 \%$ & $11 \%$ \\
Neck & $9 \%$ & $9 \%$ & $0 \%$ & $7 \%$ \\
Other & $12 \%$ & $22 \%$ & $10 \%$ & $14 \%$ \\
\hline \multirow{2}{*}{ NC, National Championship; SC, Silver Cup. }
\end{tabular}

suggesting that sweeping may represent a greater risk factor for shoulder symptoms than stone delivery.

While this study is clearly imperfect (overall participation was suboptimal and the data were subject to recall bias), there are reasons to conclude that the information obtained is reasonably accurate. The study participants were serious curlers reporting anonymously about events of considerable interest. Fully $95 \%$ of the participants identified curling as their "principal winter sport," increasing the likelihood of accurate recollection of factors affecting their performance leading up to these championship events.

Nevertheless, given the uncertainty inherent in both the exposure and injury data, it seems prudent to estimate of the time loss injury rate among competitive curlers conservatively at 2 per 1000 athlete exposures. Although this figure is limited by the study's small sample size, the data suggest that curling is a safe sport, particularly when compared with other winter sports, including skiing, snow boarding, and ice hockey (all of which have been found to have considerably higher injury rates).$^{2-5}$ Falls and sweeping the stone appear to be major risk factors for acute time loss injuries. However, we observed no association between falls or injury history and

Table 3 Curling injuries resulting in the loss of at least one day of training or competition

\begin{tabular}{lll}
\hline Self reported diagnosis & Mechanism & Time lost \\
\hline Torn rotator cuff & Fall & 4 months \\
Shoulder strain & Fall & 6 days \\
"Snapped" forearm tendon & Sweeping & 2 months \\
Back pain & Sweeping & 14 days \\
Herniated lumbar disk & Sweeping & 14 days \\
Hip contusion & Fall & 5 days \\
Torn meniscus & Fall & Months \\
Knee strain & Delivery & 3 days \\
Ankle strain & Delivery & 4 days \\
\hline
\end{tabular}




\section{Take home message}

- Time loss injuries sustained during curling were estimated to occur at a rate of 2 per 1000 athlete exposures.

- Prospective studies are needed to confirm these preliminary findings, but curling appears to be a relatively safe winter sport

alcohol consumption, even in the SC cohort (in which alcohol consumption was more prevalent). This preliminary investigation should facilitate the design of prospective injury surveillance studies needed to characterise more definitively the rate and pattern of and risk factors for curling related injuries, thereby enabling sports medicine practitioners to provide better care for, and ultimately prevent, injuries associated with this ancient sport.
Authors' affiliations

J C Reeser, Department of Physical Medicine, Marshfield Clinic, Marshfield, Wisconsin, USA

R L Berg, Marshfield Clinic Research Foundation

Correspondence to: Dr Jonathan Reeser, Marshfield Clinic, Department of Physical Medicine, 1000 North Oak Avenue, Marshfield, WI 54449, USA; reeser.jonathan@marshfieldclinic.org

Accepted 6 January 2004

\section{REFERENCES}

1 Reeser JC. Injury patterns among elite disabled standing volleyball players. Int J Volleyball Res 1999:1:12-7.

2 Hunter RE. Skiing injuries. Am J Sports Med 1999;27:381-9.

3 Smith M, Matheson GO, Meeuwisse WH. Injuries in cross-country skiing: a critical appraisal of the literature. Sports Med 1996;21:239-50.

4 Bladin C, McCrory P. Snowboarding injuries. An overview. Sports Med 1995; 19:358-64.

5 Daly PJ, Sim FH, Simonet WT. Ice hockey injuries. A review. Sports Med $1990 ; 10: 122-31$ 